\title{
Reflexões sobre o surgimento, a morte e o retorno das noções de autor e sujeito
}

Daniela Beccaccia Versiani (PUC-RJ)

GUMBRECHT E UMA POSSÍVEL TEORIZAÇÃO SOBRE O SURGIMENTO DAS NOÇÕES DE AUTOR E SUJEITO NA MODERNIDADE

Em dois capítulos de seu livro A modernização dos sentidos (1998), o medievalista, romanista e teórico da literatura Hans Ulrich Gumbrecht tematiza o surgimento, durante o período da Renascença, de duas noções: a de autor e a de sujeito.

No capítulo intitulado "Autor como máscara. Contribuição a uma arqueologia do impresso", Gumbrecht chama a atenção para a passagem de um regime de oralidade para um regime de fixação da palavra escrita - propiciado pela institucionalização da imprensa - como uma das causas plausíveis para o surgimento da noção de autor, que funcionaria como máscara de univocidade que dissimula a instabilidade e a plurivocidade de sentidos do texto escrito.

Gumbrecht afirma que essa univocidade se fundamenta na crença do leitor em uma intencionalidade do autor (GUMBRECHT, 1998, p. 100), que pode ser mais ou menos controladora das flutuações de sentido, mas que de qualquer forma precisa existir: "O que importa é a convicção de cada leitor de que essa intencionalidade existe, conferindo às variações individuais um caráter secundário” (GUMBRECHT, 1998, p. 100-101).

É nesse contexto que, segundo Gumbrecht, a imprensa passa a ter um papel decisivo na transformação de uma noção medieval para uma noção moderna de eu, esta caracterizada pela intencionalidade anterior ao texto: 
Se atribuirmos à era da imprensa a origem do papel do autor - na sua dupla função: mascarar a instabilidade do sentido e, ao mesmo tempo, assegurar-lhe uma intencionalidade -, podemos contrapô-lo ao eu que aparece nos textos medievais. $\mathrm{O}$ eu medieval é uma instância que só possui estatuto no interior de um texto determinado, ou, independente desse texto e fora dele, numa situação de execução. O 'autor' que, com o advento da imprensa, substitui esse eu, situa-se a uma distância suficientemente marcada tanto do texto como de sua encenação para fazer crer na existência de um sentido estável, por assim dizer anterior ao texto - o de uma intencionalidade preexistente. (GUMBRECHT, 1998, p. 101)

A partir de um exemplo concreto - a publicação, em 1496, do livro intitulado Cancioneiro, do poeta castelhano Juan del Encina, primeira coletânea com as obras de um único escritor a ser impressa na Espanha - Gumbrecht mostra o esforço do autor em fixar, através de prefácios e prólogos, sua intencionalidade na obra, evitando as flutuações de sentido que sua ausência no momento da recepção propiciaria. Tal preocupação pode ser notada no prólogo a uma égloga do Cancioneiro, no qual Juan del Encina resume a cena que nela vai se desenrolar: a de um pastor de nome Juan que, diante das alterações feitas por outro pastor, de nome Mateu, decide fazer a compilação de suas obras. Posteriormente, Juan del Encina - possivelmente também ator nas encenações de suas próprias obras na corte de Espanha - afirma que ele próprio decidiu reuni-las em um Cancioneiro para escapar das alterações que outros lhes faziam, nelas colocando coisas que nunca havia dito (GUMBRECHT, 1998, p. 9899).

Para Gumbrecht, a função dos prólogos, introduções e posfácios era, de um lado, orientar para o modo como textos deveriam ser recebidos e reduzir a plurivocidade que o texto impresso propiciava ao viabilizar a comunicação sem a co-presença e interação entre autor e leitor, característica da situação de comunicação oral. De outro, ao criar um afastamento entre Juan del Encina como personagem histórico, possuidor de um corpo físico - do 'autor' do Cancioneiro e do 'ator' que representava um personagem da égloga -, esses prefácios estabeleciam uma separação entre os diferentes sujeitos discursivos, base do jogo de máscaras propiciado pelo surgimento do "papel de autor".

Um outro exemplo dado por Gumbrecht ilustra a questão da intencionalidade e o jogo de máscaras que se estabelecem a partir do surgimento do "papel de autor": os inúmeros prefácios, prólogos e posfácios da Comedia de Calisto e Melibea, (1499), de Fernando de Rojas, que, igualmente, cumprem a função de orientar sua recepção. Ainda que seu autor reconheça a impossibilidade de garantir a univocidade, neles 
transparece a tentativa de "assegurar um sentido permanente, tão logo se apropriam do texto diferentes leitores/ouvintes” (GUMBRECHT, 1998, p. 102).

Essa “obsessão” em escapar da plurivocidade, em expressão de Gumbrecht, tem fundamento uma vez que, ao longo dos anos, a obra terminou sendo conhecida pelo título de La Celestina, "privilegiando o papel da alcoviteira em detrimento da intriga amorosa entre Calixto e Melibeia" (GUMBRECHT, 1998, p. 102). E isto a despeito dos esforços de Fernando de Rojas para firmar através de seus prólogos sua intenção moralizadora.

Essa intenção é afirmada no primeiro dos posfácios à obra, atribuído ao próprio Fernando de Rojas, no qual este deixa claro que a sua é uma proposta de leitura totalmente convencional. No entanto - e aqui tem início o jogo de máscaras que o "papel de autor” propicia -, num segundo posfácio, já não mais atribuído a Fernando de Rojas e sim a um corretor da impressão, é proposta uma segunda leitura, que se apresenta com um apelo mais sensual: "Com efeito, um segundo posfácio, atribuído dessa vez aO CORRECTOR DE LA IMPRESIÓN, associa uma outra forma de recepção, menos espiritual e moralizante, a leitura em voz alta, a uma reação em que se confundem diversas tonalidades afetivas". (GUMBRECHT, 1998, p. 103)

Assim, enquanto o prólogo atribuído ao próprio Rojas apresentava uma "intenção de autor" fundada em uma religiosidade moralizadora, a suposta intenção mais sensual é associada à autoria de um corretor da impressão. Segundo Gumbrecht, por detrás da figura do corretor da impressão, Fernando de Rojas, um provável judeu-ortodoxo, protegia-se da Inquisição.

Gumbrecht aponta o jogo da máscara do autor ${ }^{1}$ como um caminho de duas mãos: a intencionalidade mascara o corpo físico do autor e, por outro lado, o corpo humano mascara as intenções do autor:

A subjetividade colocava, portanto, o problema da instabilidade do sentido, resolvido pela máscara da intencionalidade. Por seu turno, a necessidade de dissimular essa intencionalidade produzia o problema da impenetrabilidade do corpo - e da materialidade do texto - como objetos de interpretação. (...).

Com o tempo, a dupla necessidade de uma articulação corporal e/ou textual que queria ser a expressão exata de uma intencionalidade e de uma interpretação capaz de retransformar essas articulações em figuras de sentidos nítidos conduziu a essa obsessão da transparência característica do século das Luzes. Não foi por acaso, portanto, que o século XVIII elevou a fisiognomonia à categoria de uma 'ciência' central e que seus autores, para justificar suas intenções, redigiam prefácios amiúde mais longos e mais complexos que os textos que eles introduziam" (GUMBRECHT, 1998, p. 105). 
Nesse ensaio, portanto, Gumbrecht demonstra a dupla dependência entre as condições históricas que propiciaram o "nascimento do autor" e o "nascimento da subjetividade moderna". De um lado, o "nascimento do autor" relaciona-se, segundo o teórico alemão, com um novo modo de produção de sentido, associado à noção de subjetividade moderna. Na modernidade, o sujeito é entendido como a instância da produção de sentidos, em oposição à idade média, na qual reinava o ato de criação divina e a imanência de sentido. Por sua vez, o surgimento do sujeito moderno propicia o nascimento do autor. Se antes do advento da imprensa a circulação de significados pressupunha a co-presença entre autor e ouvinte - ou seja, a interação direta e o consenso estabelecidos entre autor e ouvinte através dessa interação face a face com a institucionalização da imprensa passa-se a uma situação na qual a circulação de significados dispensa a co-presença física, concreta, do autor e do leitor. Surge então a necessidade de novas formas de orientação para estabelecer consensos em torno de sentidos, donde a necessidade de se estabelecer a noção de intencionalidade, fundada na figura do autor:

Com o desaparecimento da situação de interação direta, os leitores tiveram necessidade de uma nova orientação para dominar o risco de uma plurivocidade, ou mesmo de uma confusão, de sentido. O papel do autor encontrava aí a sua função específica e sua razão de ser histórica. (GUMBRECHT, 1998, p. 104)

Por fim, Gumbrecht destaca a mudança de caráter epistemológico que esta constelação de fatores propicia: "No plano epistemológico, segue-se que com o papel de autor é a era do homem como intencionalidade que se inicia” (GUMBRECHT, 1998, p. 104).

Já no ensaio subseqüente, intitulado "Garcilaso de la Vega, el Inca. Nascimento do sujeito a partir do sistema da burocracia”, Gumbrecht amplia a discussão sobre as noções de autor e sujeito, acrescentando, para além de suas relações com o surgimento da imprensa, outros dois acontecimentos: o processo de colonização da América e a instauração do sistema burocrático. Neste ensaio, o teórico alemão procura mostrar como tal constelação de fatores históricos serão desencadeantes, no Ocidente, de uma transformação de mentalidade que acabará por constituir outra visão de mundo, da qual foi possível emergir a noção moderna de sujeito.

Para fundamentar a tese de que a noção moderna de sujeito surge a partir do sistema burocrático, Gumbrecht analisa a obra Comentários Reales de los Incas, uma história do reino inca, de Garcilaso de la Vega, el Inca, nascido em Cuzco, em 1539, 
"filho de uma neta do último inca e de um soldado do séqüito de Pizarro", que emigrou para a Espanha em 1560, morrendo em Córdoba, em 1616 (GUMBRECHT, 1998, p. 113).

Comentarios Reales de los Incas recebeu várias e sucessivas leituras romantizadas, servindo, no século XVIII, no Peru, de fonte de inspiração para rebeliões anticolonialistas. Tornou-se obra canônica e Garcilaso apresentado como vítima da colonização (GUMBRECHT, 1998, p. 114). No entanto, para Gumbrecht, existe um conflito entre o desejo de seus leitores de vê-lo como vítima do domínio colonial e o papel que o próprio Garcilaso de la Vega quis desempenhar. Portanto, para o teórico alemão, a questão primordial é saber

se o desejo de seus leitores de estilizá-lo como vítima do domínio colonial não simplifica, de maneira problemática, a complexidade e o caráter contraditório daquele papel que ele quis desempenhar (e, em parte, desempenhou). (GUMBRECHT, 1998, p. 114)

Ao longo de sua argumentação, Gumbrecht mostra que a identidade que Garcilaso de la Vega construiu para si por meio da escrita é complexa, o que pode ser percebido pelo ato de renomear-se:

Seu nome de nascença, Gómez Suárez de Figueroa, compôs-se do nome espanhol da mãe (Suárez) e do nome de parentes do pai na Extremadura ('Figueroa'). Somente depois da morte do pai adotou, desde 1561 - e já na Espanha -, o seu nome 'Garcilaso de la Vega'. O aposto 'el Indio' ou 'el Inca' não surgiu antes da edição de sua primeira publicação em 1590. (GUMBRECHT, 1998, p. 114-15)

A pergunta à qual Gumbrecht procura responder em seu ensaio é se "na vida e nos livros do inca Garcilaso de la Vega realmente aparecem aspectos e estruturas que são paradigmáticos para a contribuição da imprensa e da colonização na gênese da época moderna" (GUMBRECHT, 1998, p. 115). Ou seja, em que grau a experiência histórica de Garcilaso de la Vega contribuiu para a auto-modelagem de sua identidade e subjetividade? Para responder a esta questão, Gumbrecht analisará a obra Comentarios Reales, de la Vega, focalizando dois momentos de sua trajetória: a experiência de mundo de Garcilaso em Cuzco (de 1539 a 1560), e a experiência política e cultural de Garcilaso em Madri (de 1560 até sua morte em 1616).

A partir de 1561, Madri torna-se o centro administrativo do império. No contexto de instauração plena da burocracia estatal espanhola, a questão da escrita passa a ter uma importância fundamental. Para que um nobre tivesse poder e terras era 
preciso prová-lo por escrito. É nesse sentido, portanto, que a legitimação de seus direitos passa a depender da palavra fixada por meio da escrita:

A burocracia devia decidir - como os consejos medievais - sobre a legitimidade das reivindicações ao estatuto de nobre e, sobretudo, sobre as pretensões e direitos econômicos daí advindos. O elemento estrutural decisivo de tais procedimentos repousava no fato de que não cabia à burocracia a iniciativa de contestar tais pretensões; era muito mais a obrigação dos que queriam validar direitos de propriedade e de nobreza faz̧er com que estes fossem garantidos por escrito pela burocracia. Para tal fim, precisava-se apresentar à administração uma série de documentos rigorosamente padronizados conforme o conteúdo e a forma, cuja peça central era uma documentação completa da própria genealogia [...] (GUMBRECHT, 1998, p. 120) (destaque meu).

Para Gumbrecht, a importância das escritas autobiográficas nesse período da história espanhola (séc. XVI) deve-se ao fato de encenarem "projetos de identidade pessoal". (GUMBRECHT, 1998, p. 120) Contudo, em um plano coletivo, também as crônicas tratavam de questões de identidade. Encomendadas pelo Consejo de las Indias, seus autores eram orientados sobre os critérios e forma textual a escolher. Se favorecessem os conquistadores, estes teriam possibilidades maiores de reivindicar direitos sobre as terras da colônia. Se criticassem a conduta dos conquistadores, não apenas enfraqueciam seus direitos, mas também conferiam ainda mais legitimidade ao Estado de fazerse presente nas colônias por meio da burocracia. (GUMBRECHT, 1998, p. 121)

Torna-se assim evidente que era através da escrita de cunho autobiográfico (produzida por conquistadores que reivindicavam direitos) e das crônicas (encomendadas pelo Estado) que se travavam em grande parte as disputas de poder sobre as terras das colônias. Em ambos os casos, a legitimação de direitos dependia da construção de uma identidade - fosse ela a identidade do conquistador ou a do Estado, representado pelos Reis Católicos - associada a discursos registrados na forma escrita.

É nesse contexto que Gumbrecht analisa a trajetória de Garcilaso de la Vega. Ao longo de seu ensaio, Gumbrecht mostra como, por meio da escrita, de la Vega soube reivindicar seus direitos ou mesmo construí-los, legitimando-se, por exemplo, como herdeiro de um tio. Investindo seu dinheiro na impressão de seus próprios livros, de la Vega soube construir uma identidade autoral (GUMBRECHT, 1998, p. 123) a partir da qual legitimou seus direitos.

Em seus dois ensaios, Hans Ulrich Gumbrecht tem como cerne de sua argumentação sobre o surgimento das noções de autor e sujeito a ausência corporal do criador de certo discurso. 
No primeiro deles, "Autor como máscara: contribuição a uma arqueologia do impresso", que tem por foco principal a institucionalização da imprensa, o teórico alemão mostra como a tecnologia da impressão de livros e textos, por possibilitar a circulação de discursos sem a presença física de seu criador, fez surgir também a necessidade de um certo controle na recepção do conteúdo desses escritos e sua vinculação a um autor.

Lugares para a expressão de intencionalidades desse autor, prefácios e introduções começam a ser escritos para cumprir um papel normatizador da recepção de textos, evitando ao máximo a flutuação dos sentidos decorrente da plurivocidade do texto escrito e tornando assim o texto unívoco ${ }^{2}$.

No segundo ensaio, "Garcilaso de la Vega, el Inca. Nascimento do sujeito a partir do sistema da burocracia", Gumbrecht discute outros dois fatores que, junto à institucionalização da imprensa, configuram o contexto de surgimento das noções de autor e sujeito: o processo de colonização da América e o surgimento do sistema burocrático. Em tal contexto, a ausência corporal do criador do discurso precisava ser compensada pela validação documental da autoria de um texto - fosse ele manuscrito (cartas, documentos, etc) ou impresso (autobiografias, crônicas) -, de modo a estabelecer e garantir direitos de posse na disputa de bens e de terras entre os colonizadores e o Estado. O caminho para a construção dessa validação é a escrita, de cunho autobiográfico ou documental. É através dela que o colonizador pode disputar com o Estado a posse de terras colonizadas. Daí, na última parte do segundo ensaio, Gumbrecht associar a gênese do sujeito moderno ao surgimento da burocracia.

Assim, para Hans Ulrich Gumbrecht, a autoconstrução - por meio da escrita de identidade, subjetividade e autoridade (em seu duplo sentido) é uma experiência possível apenas a partir de uma constelação de fatores históricos que a antigüidade clássica e a idade média não conheceram, e que transformariam para sempre o processo de constituição da realidade no mundo ocidental (GUMBRECHT, 1998, p. 112): a invenção e institucionalização da imprensa, a descoberta da América e sua colonização (fatores que inauguram a necessidade de garantir a posse de terras sem a presença física do possuidor) e a instauração do sistema burocrático, com a proliferação de documentos. Segundo o pensador alemão, as operações de construção de identidade, subjetividade e identidade autoral teriam ocorrido, portanto, em um momento em que estavam plenamente configuradas as possibilidades de "institucionalização da subjetividade". (GUMBRECHT, 1998, p. 133-4) ${ }^{3}$

A partir da argumentação de Gumbrecht, podemos inferir que o surgimento das noções de identidade, subjetividade e autoria está atrelado à própria ausência, ou 
melhor, ao não estar presente. No campo da produção artística ou ficcional, tal ausência se deve à circulação de discursos sem a presença física de quem os produziu, possível apenas pela técnica da impressão. No campo de produção de discursos autobiográficos e documentais, tal ausência se deve às grandes descobertas - de terras distantes e ao sistema burocrático, no qual propriedade e posição social passaram a ser asseguradas não mais pela palavra oral, que dependia da presença do possuidor (e de toda uma série de convenções sociais que formavam a mentalidade feudal, na qual a palavra - oral - dada tinha valor de contrato), mas pela palavra escrita, que passava agora a garantir direitos de herança e propriedade. Como afirma Gumbrecht (1998, p. 133) documentos têm a função de "representar sujeitos na ausência de seus corpos" ${ }^{4}$.

\section{BURKE: A MORTE E O RETORNO DAS NOÇÕES DE AUTOR E SUJEITO NA CONTEMPORANEIDADE}

Se, subscrevendo a explicação de Gumbrecht, o contexto histórico que moldou a modernidade trouxe a possibilidade de configuração das noções de autor e sujeito, qual seria hoje o enfoque dado a tais noções?

Uma das questões mais complexas na passagem do século XX para o XXI diz respeito às dificuldades criadas pela afirmativa pós-estruturalista da 'morte do autor' - que veio a reboque da afirmativa da 'morte do sujeito' - diante da necessidade de expressão de discursos minoritários e de novas subjetividades bem como dos questionamentos éticos com os quais intelectuais temporalmente localizados pósSegunda Guerra Mundial, pós-movimentos de 68, pós-feminismos, pós lutas pelos direitos civis das minorias, se defrontaram. (HUYSSEN, 1991, 1993) ${ }^{5}$

A reflexão sobre as conseqüências éticas e políticas dessas duas afirmativas, que marcaram boa parte das discussões no campo filosófico e literário a partir da segunda metade do século XX, tem estimulado o empenho de alguns teóricos contemporâneos da cultura em retomar as noções de sujeito e autor a partir de outras necessidades, outros pressupostos, e também outros objetivos, entre os quais aquele de retomar tais conceitos de modo produtivo, como agenciadores, facilitadores ou catalisadores da percepção de novas subjetividades e não como empecilhos para a sua visualização.

Ao evocar o "caso Paul de Man" no prólogo a The Death and Return of the Author. Criticism and subjectivity in Barthes, Foucault and Derrida (BURKE, 1993) ${ }^{6}$, Seán Burke dá

144 - Lejgun \& mein: Rrvista dr hiteratura e Divgrsidadr Cultural, v. 6, № 4, 2008 
início a uma reflexão que poderia ser lida como avaliação das conseqüências éticas, no que concerne à relação entre intelectuais e produção de teorias, daquela que talvez tenha sido a mais polêmica afirmativa pós-estruturalista acatada pelos desconstrucionistas da Escola de Yale: a da "morte do autor". Seán Burke abre sua discussão sobre as questões éticas suscitadas pela desarticulação das categorias autor/texto exemplificando-as com o "caso Paul de Man".

Como aponta Seán Burke, a divulgação dos 170 artigos publicados entre 1940 e 1942 pelo jovem Paul de Man no jornal colaboracionista belga Le Soir, não apenas desencadeou uma série de questionamentos entre os teóricos formados pelo pensamento desconstrucionista sobre a validade acontextual e atemporal da dissociação autor/texto - premissa que Paul de Man ajudou a modelar -, mas os forçou também a reconduzir o olhar sobre sua vida, sua figura histórica, que agora era percebida com maior complexidade. (BURKE, 1993, p. 2) Assim, ironicamente, questões relativas à relação autor/texto foram reinseridas no circuito de discussões acadêmico justamente por meio da figura de um dos teóricos que mais colaborou no processo de desarticulação de tais categorias.

Burke assim define as posturas de Paul de Man com relação ao tema da autoria no decurso de sua trajetória intelectual:

Na primeira fase de sua carreira como teórico da literatura, de Man adotara uma descrição fenomenológica rigorosa da questão da autoria por meio da qual o self era totalmente esvaziado de qualquer conteúdo biográfico, o que resultava na constituição de uma subjetividade transcendental sem qualquer preocupação histórica ou empírica. Posteriormente, como desconstrucionista, rejeitou a crítica centrada no autor de modo distinto, afirmando que não existe sujeito estável da escrita de nenhum feitio, seja ele transcendental ou empírico. Em ambas as fases de sua carreira, o sujeito biográfico é inteiramente eliminado: vida e personalidade do autor desaparecem irremediavelmente na máquina textual. (BURKE, 1993, p. 2)

O aparecimento dos artigos pró-nazismo escritos no jornal Le Soir por Paul de Man na juventude levaria alguns críticos a associar as premissas epistemológicas que sustentavam as suas afirmativas teóricas de negação da biografia e do autor a uma estratégia em sua própria defesa, um modo de "esvaziar e evitar [to (a)void] - seu self histórico”. (BURKE, 1993, p. 2) Uma estratégia que teria por aliada a noção desconstrucionista de "textualização da história" (BURKE, 1993, p. 2), que possibilitava a leitura daqueles artigos como "representativos" de sua própria história, destacados de seu autor. 
Além dessa, outras suposições foram levantadas por críticos em torno do caso. Alguns partiam do pressuposto de que não havia ligação entre os escritos do jovem autor e as afirmativas do intelectual maduro; outros, ao contrário, partiam em busca de alguma coerência entre os textos produzidos nos dois diferentes momentos de sua trajetória intelectual. Nesse sentido, ora os escritos da maturidade eram vistos como independentes, ora como expiação das afirmativas da juventude. (BURKE, 1993, p. 3)

Ao levantar essas diferentes posições diante da relação texto/autor, teórico/ produção teórica, Seán Burke chama a atenção para o fato que, além das questões éticas e morais suscitadas pelo episódio quanto ao papel dos intelectuais e a responsabilidade social sobre o conteúdo de seus escritos, o "caso Paul de Man” fez também ressurgir, para serem utilizados nos argumentos tanto de seus defensores quanto de seus detratores, alguns dos principais tópicos da crítica centrada no autor que haviam sido abandonados pelo desconstrucionismo: intenção autoral, autoridade, biografia, responsabilidade, obra e autobiografia. (BURKE, 1993, p. 4-5)

A questão da intenção, argumenta Burke, foi focalizada ora a partir de uma perspectiva desconstrucionista, marcadamente anti-intencionalista, ora contextualista e pró-intencionalista. Ambas, contudo, partiam do pressuposto comum de reconhecimento da intenção, uma vez que assumiram que "o que ele quis dizer importa, que o que ele quis dizer significa algo para nós, e que sua obra posterior é governada por boas ou más intenções em relação àqueles artigos colaboracionistas". (BURKE, 1993, p. 4)

Segundo Burke, as discussões em torno da autoridade de De Man como teórico e filósofo trouxeram de volta a noção de hierarquia de discursos, uma vez que "o fato de Paul de Man, tal como Heiddeger, ser um autor-filósofo levou muitos críticos a ver sua ligação com a ideologia nacional-socialista como tendo conseqüências mais perniciosas do que as de personagens culturais não-discursivos, tais como músicos, enxadristas, entre outros". (BURKE, 1993, p. 4)

Ora para defendê-lo, ora para acusá-lo, dados biográficos e contextuais foram amplamente utilizados nos debates em torno do caso, da mesma forma que a questão da responsabilidade autoral prevaleceu sobre a afirmativa de sua ficcionalidade:

Todos os envolvidos na controvérsia concordaram que de Man deveria ser obrigado a prestar contas pelo que escreveu. Em relação a esta questão, a teoria parece abandonar ou suspender a idéia de que o autor é uma mera ficção ou traço da linguagem, pois, se a autoria era de fato uma ilusão textual, não haveria nada a responder, restando apenas lembrar ao mundo que na realidade o texto "Paul de Man" nada sinaliza e nada significa. Fato é que seus amigos teóricos defenderam de Man enquanto 
pessoa e, com freqüência, com considerável dignidade e paixão. Isto no mínimo confirma que, em primeiro lugar, a assinatura ‘Paul de Man’ é algo maior que um mero efeito textual, e, em segundo lugar, que tal assinatura associa de Man, ética e existencialmente, aos textos que escreveu. (BURKE, 1993, p. 5)

Da mesma forma, continua Seán Burke, a existência de um corpus teórico - obra - associado a Paul de Man não foi questionado em nenhum momento do debate. Nenhuma das tentativas de dar sentido às relações entre os escritos do jovem intelectual e o teórico da maturidade - fossem elas fundadas sobre a idéia de que havia uma continuidade de pressupostos entre os escritos da maturidade e os escritos da juventude, ou de que os últimos eram a retratação ideológica dos primeiros - abandonou o pressuposto de que havia um corpo teórico ligado ao autor. (BURKE, 1993, p. 5)

Por fim, o discurso autobiográfico, acrescenta Burke, foi igualmente mencionado por seus defensores e detratores como recurso para fundamentar ora a hipótese de que a prosa teórica de Paul de Man seria não a simples expressão autobiográfica, mas a sua supressão; ora uma forma indireta de confissão. (BURKE, 1993, p. 6)

O prólogo de Seán Burke, no qual reflete sobre o debate em torno de Paul de Man, pode ser lido como um estudo de caso que lhe servirá como ponto de referência para a discussão que pretende manter ao longo de The Death and Return of the Author, discussão esta que gira em torno da tentativa de retomada - em termos totalmente diversos da crítica vida-obra e do positivismo biográfico do século XIX - da noção de autor histórico, empírico, ligado à vida, algo que a teoria desconstrucionista, de vertente anglo-americana, ao trabalhar predominantemente com a noção de autor como categoria a-histórica e acontextual, supostamente abandonara. Ao mesmo tempo, é também a tentativa de mostrar que, de fato, o conceito de autor - e com ele outros tópicos abandonados pela desconstrução, tal como intenção e voz autoral, relação vida/obra, autobiografia e biografia - retorna ainda mais poderoso exatamente através dos discursos teórico-críticos que pretendem afirmar seu desaparecimento. (BURKE, 1993, p. 6-7)

Como se sabe, a transferência das afirmativas pós-estruturalistas, surgidas em contexto francês, para o contexto acadêmico estadunidense resultou numa reorganização de muitos de seus pressupostos a partir de um substrato teórico-epistemológico no qual a tradição imanentista, firmada já há algumas décadas pelo new criticism, se unia a uma quase inexistente tradição filosófica. (Huyssen, 1991, 1993; Olinto, 1993) 7 Mas qual era o contexto teórico-filosófico francês no qual Barthes, Foucault e Derrida se formaram? Em sua introdução, Seán Burke procura mapear tal contexto. 
Reconhecendo os diferentes matizes do pensamento fenomenológico na França, Burke afirma que "todas as versões da fenomenologia desenvolvidas durante esse período tinham em comum o foco sobre a questão da subjetividade" somada ao ideal da liberdade individual. (BURKE, 1993, p. 11) Para Burke, a predominância de uma leitura existencial da fenomenologia durante a década de 1940 é resultado da ascensão cultural e intelectual de Jean-Paul Sartre naquele período, "ascensão comparável apenas à de Voltaire nos dois séculos anteriores" (BURKE, 1993, p. 11):

Como filósofo, dramaturgo, romancista, jornalista e ativista político, Sartre estendeu da filosofia para a literatura e a política a noção de uma subjetividade livre, proporcionando à sua geração o modelo de autor engajado, de escritor politicamente empenhado, cujo trabalho e cujas atividades afirmavam os ideais de liberdade pessoal e política em todos os aspectos da existência cotidiana. Tal modelo deixou uma profunda e duradoura marca em Barthes, Foucault e Derrida. (BURKE, 1993, p. 11)

Segundo Seán Burke, a figura de Sartre e o tema da consciência exercem um papel fundamental no início da carreira intelectual desses três teóricos:

A formação intelectual de Barthes, Foucault e Derrida ocorreu em um ambiente no qual a idéia de sujeito detinha a mesma ascendência que a linguagem teria no último quarto do século XX. A consciência fenomenológica, ao invés das estruturas lingüísticas, fundamentava suas primeiras pesquisas. (BURKE, 1993, p. 11)

Como enfatiza Burke, no início de suas carreiras, Barthes, Foucault e Derrida estiveram imersos nas questões centrais à fenomenologia: sujeito e consciência. Somente com a revolução lingüística representada pelo impacto das publicações de Tristes Tropiques, de Claude Lévi-Strauss, e The Agency of the Letter in the Unconscious, Or Reason Since Freud, de Jacques Lacan, em 1955 e 1957, respectivamente, ocorre um questionamento radical desses pressupostos no pensamento dos três filósofos que posteriormente viriam a ser denominados pós-estruturalistas. Assim, para Burke, a lingüística estrutural - que fora concebida em berço de língua francesa com a publicação em 1915, na França, de Course in General Linguistic, do lingüista suíço Ferdinand de Saussure - precisou ser adotada pelo formalismo russo e depois migrar por diferentes disciplinas - a antropologia de Lévi-Strauss, a psicanálise de Lacan - para só então retornar ao que considera seu "campo natural de aplicações", os estudos literários, através de Barthes, Derrida e Foucault. (BURKE, 1993, p. 12)

Como afirma Burke, os pressupostos intrínsecos ao modelo lingüístico têm conseqüências diretas para a questão do sujeito, que sofre necessariamente uma radical 
mudança de status em relação à produção do conhecimento, e também para a relação do sujeito com o mundo. A desnaturalização da linguagem a que conduz a afirmativa da "arbitrariedade do signo" de Saussure - a partir da qual a relação entre significante e significado deixa de ter uma correspondência natural para basear-se na relação convenção/diferenciação - está na base das análises das relações sociais de Lévi-Strauss e das concepções sobre o inconsciente de Lacan. (BURKE, 1993, p. 13)

Assim, ao traçar as linhas de força que modelaram o contexto no qual surge o pós-estruturalismo na França e a partir do qual considera devam ser compreendidas as afirmativas pós-estruturalistas de 'morte do autor' e a sua postura anti-subjetivista, Burke pode enfim estabelecer as diferenças entre a limitada reação contra o positivismo biográfico adotada anteriormente por movimentos como o formalismo russo e o new criticism americano, nos quais o conceito de autor não desaparecera em definitivo, e a efetiva dissolução do conceito pelos pós-estruturalistas. (BURKE, 1993, p. 14) Enquanto a questão do autor no formalismo russo e no new criticism limitava-se a uma reação contra o positivismo biográfico, dominante no século XIX, no pós-estruturalismo a dissolução do conceito de autor veio a reboque da discussão maior - em torno da dissolução do sujeito - que ocupava as ciências humanas e a filosofia.

Para Burke, a postura anti-subjetivista dos pós-estruturalistas deveria ser compreendida a partir da "intersecção entre a fenomenologia e o estruturalismo" (BURKE, 1993, p. 14), mas também como uma questão que ultrapassava o plano literário e estava inserida no contexto de discussões que envolviam as ciências humanas em geral.

Assim, a declaração pós-estruturalista da "morte do autor" deveria ser considerada em termos epistemológicos e associada à mudança geral de pressupostos que ocorria desde a "revolução" operada pela lingüística estrutural, ou seja, ao fim do sujeito compreendido como anterior à linguagem, concebido como centro transparente, transcendente - e eu acrescentaria neutro - da produção do conhecimento. Nesse sentido, enquanto a resistência à noção do autor nas teorias formalistas se limitava à estratégia de "estabelecer um campo coerente para os estudos críticos" através da eliminação no objeto literário de especulações em torno de dados biográficos e psicológicos sobre o autor, que remontavam às estratégias interpretativas do século XIX, no caso do pós-estruturalismo a questão é muito mais ampla. (BURKE, 1993, p. 15)

Se nas teorias formalistas a exclusão da figura do autor respondia à necessidade metodológica de uma perspectiva teórica para a qual "a morte ou desaparecimento do autor não estava em debate, mas sim a incompatibilidade de categorias autorais com análises imanentistas" (BURKE, 1993, p. 16), no caso do pós-estruturalismo, "o 
surgimento da escrita é a priori identificável com o desaparecimento do autor”. Ou seja, a exclusão do autor vai muito além de uma estratégia metodológica, passando, nas palavras de Burke, para uma "afirmativa ontológica sobre a própria essência do discurso". (BURKE, 1993, p. 16) Se de um lado esta colocação de Burke pode parecer uma leitura apressada da teoria que também propôs o fim do essencialismo, de outro aponta para um certo dogmatismo que merece ser questionado:

Declarações desse tipo - características do moderno anti-autorialismo - não são feitas através de uma linha argumentativa ou de uma moldura discursiva convencional. O que se expõe não é oferecido como algo aberto a questionamentos. O leitor é convidado ou a aceitar a verdade do que está sendo dito como nada menos que um fato da escrita, ou é levado de volta, de modo nostálgico, a um humanismo que já não é sustentável no atual contexto teórico. E, em geral, tem sido esta de fato a reação padrão à declaração da morte do autor. (BURKE, 1993, p. 17)

Ao apresentar a discussão da morte do autor inserida na discussão da morte do sujeito, Seán Burke contextualiza filosófica e teoricamente os discursos e textos que anunciaram a morte dessas categorias. Burke considera que tais discursos não foram suficientemente analisados pela crítica, seja devido ao dogmatismo dos próprios pósestruturalistas, que tomaram o desaparecimento da categoria de autor como um "artigo de fé" (BURKE, 1993, p. 17), seja porque aqueles que saem em defesa da categoria de autor normalmente o fazem a partir de uma "postura humanista fundamentalmente fechada ao debate em sua oposição à redução da literatura a um jogo impessoal de significação" (BURKE, 1993, p. 17). Nesse sentido, podemos concluir que Burke, no momento em que propõe o retorno à discussão do autor, também propõe a retomada da questão do sujeito. Mas em que termos?

A crítica de Burke ao pós-estruturalismo, mas sobretudo à vertente anglo-americana da desconstrução (cf. nota 5), além de dar a exata dimensão das disputas teórico-críticas franco-anglo-americanas, também faz ver que, embora interligadas, as afirmativas da morte das categorias do autor e do sujeito têm amplitudes e conseqüências distintas. Burke alerta para o equívoco de supor que "Homem" e "Autor" se refiram ao mesmo Sujeito, ou que autor seja uma instância específica do "Homem". (BURKE, 1993, p. 105)

No subcapítulo intitulado "Subjetividades", pertencente ao mesmo livro, Seán Burke aponta para a necessidade de compreender as diferentes instâncias em que estes dois conceitos circulam, tomando o cuidado de não reduzir um ao outro: 
Que os destinos do homem e do autor estão entrelaçados - e que eles se tornarão ainda mais inextricáveis caso nossas idéias de mundo e de texto se tornem mais e mais coesas - é incontestável. Isto contudo não significa que em toda e qualquer época e lugar eles possam ser reduzidos um ao outro sem problemas. (BURKE, 1993, p. 106)

Segundo Burke, a sobreposição entre os dois conceitos se deve, por um lado, à confusão geral em torno da palavra sujeito, que ao longo de sua história assumiu diferentes sentidos, muitas vezes opostos: se inicialmente "sujeito" assumira o sentido de subjectus, o sujeito subalterno em uma relação de vassalagem ou subordinação a uma instância ou sujeito hierarquicamente superior, posteriormente passou também a denotar a soberania do ego transcendental das filosofias da consciência (BURKE, 1993, p. 106). Por outro lado, tal sobreposição se deve às relações filosóficas que a palavra sujeito mantém com conceitos tais como "self, cogito, ego, ego transcendental, consciência, conhecimento e criatividade”. (BURKE, 1993, p. 107) É nesta complexa relação entre diferentes conceitos, que muitas vezes se fundem e sobrepõem, que estão inseridas as declarações de morte do sujeito e de morte do autor.

Como Seán Burke procura mostrar, várias e distintas concepções de sujeito e autor estão em jogo nessas afirmativas: ora se trata do sujeito transcendental da filosofia clássica, ora do sujeito da consciência e do conhecimento da fenomenologia, ora do autor entendido como princípio formal a dar sentido ao texto, ora do autor em seu sentido empírico, psicobiográfico. Todas estas concepções se conectam em suas respectivas "mortes":

A morte do sujeito transcendental está ligada à morte do sujeito do conhecimento, que por sua vez está ligada à morte do autor como princípio textual formal, a qual, por sua vez, está ligada ao desaparecimento da intencionalidade psicobiográfica.

Essa corrente de associações é o fundamento 'filosófico' da morte do autor. O que se afirma, no fundo, é que a negação do cogito apaga todas as formas de subjetividade e os predicados delas derivados. (BURKE, 1993, p. 107)

É contudo contra o sujeito concebido a priori, fora do espaço, do tempo, da linguagem, da história e da cultura, que os discursos da morte do sujeito se dirigem. A partir deste reconhecimento, Burke faz algumas perguntas importantes:

De fato, é inegável que, em conjunto, Lévi-Strauss, Lacan, Althusser, Derrida, Barthes e Foucault trouxeram vigor ao período ao se posicionarem contra a idéia de um sujeito apriorístico, situado fora do espaço e do tempo, da linguagem, da história, da 
cultura e da différance. Mas esta investida violenta põe abaixo todos os significados de sujeito, tal como afirmam alguns? O conceito de autor só é sustentável se uma subjetividade transcendental for assim constituída? Ou, para formular a questão não formulada e logicamente anterior: como se constitui o conceito de autor tomando-se por base uma subjetividade transcendental? (BURKE, 1993, p. 107)

Buscando respostas a essas questões, Burke dirá que qualquer perspectiva crítica que associe o autor ao sujeito transcendental deverá necessariamente fazer uma completa separação entre o autor concebido como agenciamento empírico e o autor concebido como princípio puramente ontológico ao texto (BURKE, 1993, p. 107): "Para ser concebido em termos transcendentais o autor deve ser esvaziado de todo e qualquer conteúdo psicológico e biográfico: um sujeito transcendental personalizado e psicobiograficamente constituído é impensável." (BURKE, 1993, p. 107)

Concepções de subjetividade transcendental partem desta separação inicial, tal como se verifica na formulação kantiana de sujeito, entendido como "percepção transcendental, unidade de consciência a priori, puramente formal que garante o conhecimento objetivo" (BURKE, 1993, p. 107-8) e, da mesma forma, na conceituação de sujeito da fenomenologia husserliana, sujeito destituído de "conteúdo psicológico ou empírico e alocado fora do espaço e do tempo". Como enfatiza Burke, "é preciso ser extra-mundana para que uma subjetividade seja transcendental" e, para complementarmos a argumentação de Burke: “o 'eu' não tem nenhuma existência no mundo fenomenológico: é um sujeito puramente lógico”. (BURKE, 1993, p. 108)

Segundo Seán Burke, tal concepção de subjetividade transcendental transferiuse para o plano da crítica literária e, a partir dela - ainda que muitas vezes tenha acabado por deslizar para o psicologismo que Husserl pretendia evitar -, o autor passou a ser entendido como um princípio puramente formal de verificação e validação do sentido do texto. (BURKE, 1993, p. 108) Assim, na crítica fenomenológica mais fiel ao sujeito husserliano - e portanto distanciado do psicologismo subjetivista -, a concepção de autor passa a servir de instância de confirmação do sentido do texto, cumprindo, em escala textual, função semelhante àquela do sujeito transcendental que possibilita o conhecimento objetivo e a verdade universal:

Kant e Husserl formularam o postulado de um ego transcendental necessário para se garantir a objetividade do nosso conhecimento sobre o mundo. Somente através desse postulado o conhecimento individual poderia se reconciliar com o conhecimento universal. (...) Dada a indeterminação do sentido textual na ausência de uma norma adjudicativa qualquer, a premissa da intenção autoral é condição epistemológica 
necessária à existência de sentido objetivo. $\mathrm{O}$ autor assim constituído não é nem local de forças, nem lugar psicobiográfico, mas metáfora para o texto, operando no nível mais consistente e plausível de interpretação, um princípio puramente formal de determinação do conhecimento textual. Intenção não é aqui o embate vívido e agonísitico de um autor com seu material, mas, ao contrário, o tribunal último no qual os criticismos competem, reivindicam suas verdades, e consentem em ser julgados. Portanto, o lugar do autor fica acima e além do nível em que os sentidos textuais podem estar em conflito e em contradição, e é através de sua ação unificadora que tais conflitos podem ser neutralizados no interesse de uma 'verdade' mais elevada, auto-evidente, ou no interesse de determinado sentido. (BURKE, 1993, p. 109)

É a tal noção de autor, afirma Burke, transcendente porque concebido como não-empírico e cuja intenção é tomada como critério indiscutível de autenticação do sentido, que os discursos anti-autor se dirigem: se para Barthes tal noção de autor acaba por provocar o fechamento das possibilidades interpretativas, para Foucault acaba por funcionar como um princípio que reduz as possibilidades de proliferação de sentidos. No entanto, continua Burke, tomar seu contrário - a impessoalidade - como único caminho alternativo é recair na mesma transcendência da qual se pretendia escapar. (BURKE, 1993, p. 109) Esta aporia é reconhecida pelo próprio Foucault e destacada por Burke:

De modo similar, mas inversamente, é evidente o modo como a doutrina da impessoalidade pode implicar a idéia de um autor transcendentalmente distante. O próprio Foucault faz um alerta contra o idealismo transcendental recrudescente no conceito de écriture: 'a noção de escrita parece deslocar as características empíricas do autor em direção a um anonimato transcendental'. De fato, com o texto impessoal, é impossível determinar se o que surge é a transcendência da linguagem ou a transcendência de seu autor. (BURKE, 1993, p. 110)

É neste ponto, a meu ver, que Seán Burke dá sua maior contribuição ao debate contemporâneo sobre as concepções de autor e sujeito. Tendo até então trabalhado no sentido de explicitar os pressupostos e conceitos que estão em disputa no debate em torno da "morte do autor" - de um lado as categorias transcendentes da crítica fenomenológica alinhada a Husserl, na qual autor é tido como autoridade cuja função é validar a "verdade" do texto, de outro a crítica pós-estruturalista, que oferece como alternativa àquela concepção de autor a impessoalidade, correndo o risco de cair na transcendência da linguagem ${ }^{8}$-, Burke agora acrescentará à discussão um novo elemento: o discurso autobiográfico. Um elemento que obrigará à relativização de todas 
as afirmativas e evitará a recaída na lógica da transcendência através da historicização do autor empírico. Para fundamentar tal posição, Burke recorrerá a dois pensadores que fizeram a crítica às filosofias da transcendência: Nietzsche e o próprio Foucault.

Seán Burke aponta que concepções biográficas de autor abalam não apenas o próprio conceito de autor como categoria transcendente e a alternativa da impessoalidade textual intrínseca aos discursos anti-autor, mas as próprias condições de produção de "verdade" e "objetividade" universais, que se fundam no distanciamento autor/texto:

Constituir um sujeito biográfico ou um sujeito do desejo em um texto que exibe o não envolvimento transcendental de seu autor abala não apenas o soberbo distanciamento desse autor, mas as próprias declarações de verdade e objetividade que tal distanciamento reforça. (BURKE, 1993, p. 111)

Textos verificativos são facilmente identificados por uma subjetividade transcendente ou por uma impessoalidade textual que, no discurso filosófico, passam a constituir a própria condição de produção da verdade objetiva. Tendo por principais interlocutores as concepções de sujeito cartesiano e kantiano, será contra o discurso filosófico impessoal, anônimo, validado pela transcendência de um "sujeito desinteressado", afastado do texto, que Nietzsche dirigirá suas críticas. E o fará por meio do discurso autobiográfico:

$\mathrm{Na}$ modernidade, Nietzsche, mais que qualquer outro filósofo, esteve profundamente consciente desses problemas. O aspecto autobiográfico de seu texto, suas divagações e digressões excêntricas e altamente pessoais operam contra o ideal filosófico do presunçoso desinteresse. Além disso, Nietzsche não apenas aplicou essa estratégia aos seus próprios textos, mas buscou revelar a ilusão do anonimato transcendental do discurso filosófico, contrapondo a personalidade e os preconceitos do autor filosófico à aparente objetividade de seu sistema. (BURKE, 1993, p. 111)

Ao inscrever o filósofo-autor no sistema, Nietzsche questiona as noções de "conhecimento", "verdade" e "moralidade", compreendendo-as como conseqüências de procedimentos adotados pelo filósofo desde o princípio de sua escrita ou reflexão:

Filósofos apresentam suas conclusões como resultado de investigações estritamente desinteressadas sobre os problemas da verdade, do conhecimento e da moralidade, como conseqüências que dependem apenas de procedimentos puramente racionais. $\mathrm{Na}$ visão de Nietzsche, contudo, tal meta é estabelecida desde o início. O texto é escrito de 
trás para frente, os raciocínios do filósofo das conclusões para as premissas. (BURKE, 1993, p. 112)

Burke explica que, para Nietzsche, na tradição filosófica que está sob sua mira, "afirmar a impessoalidade de um sistema filosófico é o primeiro passo para atribuir a esse sistema um valor transcendental e vice-versa" (BURKE, 1993, p. 113). É nesse sentido que, ao inscrever o sujeito autoral dentro do sistema por ele observado e/ou descrito, Nietzsche abala as teorias da transcendência do sujeito e, com elas, as noções universais de verdade e objetividade.

Longe de endossar uma à outra, de pertencer uma à outra enquanto aspectos do mesmo sujeito, a subjetividade transcendental dos sistemas filosóficos e a subjetividade do autor trabalham uma contraa outra: a inscrição de uma biografia, um desejo biográfico e biológico interno ao texto resiste a qualquer teologia do sujeito idealista. Duas subjetividades marcadamente distintas estão em oposição: uma, transpessoal, extramundana, normativa e formal; a outra, intra-mundana, biográfica, um sujeito do desejo, uma vez que anseia por um mundo melhor, um sujeito 'material'. (BURKE, 1993, p. 113)

Nesse sentido, trata-se de um equívoco apontar Nietzsche como precursor das teorias desconstrucionistas que professam o desaparecimento do autor:

A recepção equivocada de Nietzsche como um proto-desconstrucionista que advoga pelo desaparecimento do autor é resultado direto da negligência em relação a esta distinção. De fato, o segmento de The Will to Power no qual se baseia a apropriação anti-autor de Nietzsche se dirige exclusivamente contra os sujeitos cartesiano e kantiano: uma intensa e concentrada crítica filosófica à egologia onto-teológica das filosofias da consciência é direta e equivocadamente tomada como ataque ao autor. De fato, não poderia haver leitura mais errônea, pois - virtualmente sozinho entre filósofos - Nietzsche insistia sobre as mais estreitas ligações entre o homem e suas obras, chegando até mesmo a ver essa conexão como indicativa do valor de um sistema de pensamento. (BURKE, 1993, p. 113)

Segundo Seán Burke, o mergulho de Nietzsche na vida mesma e a "humanização do conhecimento" - derivados da conexão entre sujeito e vida, autor-filósofo e texto - são os elementos a possibilitar que o pensamento filosófico se liberte de sua transcendência e o conhecimento se torne relativo, mediado, perspectivo (BURKE, 1993, p. 113-14). Por sua vez, a crítica de Nietzsche ao sujeito transcendente abre 
caminho para repensarmos a questão da subjetividade dentro de uma perspectiva histórica (BURKE, 1993, p. 114). É dentro desta perspectiva que Burke vê o trabalho do próprio Michel Foucault: 'Em 'The Subject and Power', Foucault afirma de fato que o objetivo do pensamento contemporâneo é 'promover novas formas de subjetividade através da recusa ao tipo de individualidade que tem sido a nós imposta por muitos séculos.” (BURKE, 1993, p. 115)

Assim, Seán Burke mostra que na versão pós-estruturalista vinculada à contribuição de Foucault, em sua articulação com reflexões teórico-filosóficas que remontam a Nietzsche e à chamada filosofia anti-humanista, a concepção de sujeito a ser abalada é de fato a concepção de sujeito transcendental, anterior à linguagem, fora da história e do tempo.

Ao trazer, através de Nietzsche e Foucault, a discussão sobre autor e sujeito para uma dimensão empírica, histórica e contextualizada, Seán Burke abre caminho para o debate sobre as dificuldades políticas suscitadas pela declaração da morte do autor e do sujeito, não apenas no espaço intra-muros da academia, como exemplificado pelo “caso Paul de Man”, mas também no espaço fora dela, permitindo ampliar a discussão para a necessidade de articularmos textos e comunicados a noções alternativas de autor e sujeito; noções estas capazes de dar conta da necessidade de expressão de novas subjetividades em um contexto no qual a percepção da sociedade como um contexto multicultural é cada vez mais forte. ${ }^{?}$

Em um momento em que cada vez mais os estudos literários e culturais se aproximam da antropologia, em que a relativização de afirmativas e verdades se torna cada vez mais necessária para a compreensão das questões contemporâneas, em um contexto cada vez mais percebido como multicultural, no qual ganham visibilidade novas subjetividades, parece cada vez menos plausível - tal como ocorria nas versões menos politizadas da vertente pós-estruturalista e de sua recepção anglo-americana pela assim denominada desconstrução - a desvinculação de textos, enquanto discursos e comunicados, de seus autores empíricos, com suas ideologias, crenças e, sobretudo, pertencimentos a grupos sociais e culturais variados e variáveis.

Obviamente não se trata de retomar as noções de autoria e sujeito fundadas em pressupostos metafísicos ou transcendentes. Tampouco de retomar simplórias explicações causalistas em torno das categorias "vida do autor" e "sua obra". Ao contrário, parece cada vez mais necessário compreender os conceitos de autor e sujeito a partir de suas vinculações com contextos históricos, sociais e culturais percebidos como multifacetados e plurais. Sobretudo quando pensamos em sujeitos e autores de carne 
e osso - tornados visíveis desde os movimentos pelos direitos civis dos negros, das mulheres, dos homossexuais e outras diferentes minorias - e que, muitas vezes, estão também eles, tal e qual Garcilaso de la Vega, em busca da afirmação e garantia de direitos, por meio não apenas da proferência de discursos orais, mas também da produção de textos escritos, sejam eles considerados literários ou não.

$\mathrm{E}$, no entanto, essa perspectiva não me parece suficiente.

Para além do que sugere o texto de Seán Burke, de meu ponto de vista, é preciso atribuir sentidos aos conceitos de autor e sujeito que os tornem produtivos não apenas para a percepção de novas subjetividades, pois desse modo partimos do pressuposto de que tais subjetividades são anteriores aos próprios conceitos que elaboramos. É preciso - e aqui se trata de uma afirmativa definitivamente vinculada a pressupostos construtivistas - atentar para a própria construção, através dos conceitos que elaboramos, de contextos e realidades multifacetadas e plurais.

Nunca é demais lembrar que o contexto moderno de surgimento das noções de autor e sujeito por mim aqui apresentado foi modelado, de modo plausível, a partir do presente, por um pensador meu contemporâneo de nome Hans Ulrich Gumbrecht; e que o contexto filosófico e teórico-literário do período que vai de meados do século XX ao início do século XXI aqui apresentado foi modelado, de modo plausível, por um pensador meu contemporâneo de nome Seán Burke. Tampouco é demais lembrar que o pensamento de ambos os autores foi aqui justaposto, resumido e recortado por mim. Nesse sentido, o que parece necessário é reconhecer a contribuição dos sujeitos - através dos conceitos que constituem e da maneira que os apresentam - na construção não apenas da realidade, mas da própria episteme. (SCHMIDT, 1994, 1989) Resta saber se desejamos que tal episteme esteja apta ou não a construir realidades multiculturais e plurais. Essa perspectiva, declaradamente construtivista (SCHMIDT, 1994, 1989; VERSIANI, 2005), acredita que conceitos são elaborados por sujeitos que, em sua historicidade, constroem as realidades em que esses mesmos conceitos e sujeitos circulam, ao mesmo tempo em que sujeitos e conceitos, em sua historicidade, são por tais realidades construídos. Ou seja, a própria realidade - seja ela uma realidade passada, seja ela uma realidade contemporânea - depende de conceitos para constituir-se ou não enquanto multicultural e plural. Resta saber como nós - os chamados intelectuais - nos inserimos nesse circuito: se como criadores "da morte" de novas e alternativas subjetividades, ou como criadores de conceitos que possibilitam sua existência e a própria possibilidade de reivindicação pelos seus direitos.

\section{$\operatorname{son}$}




\section{NOTAS}

1 Valeria a pena, aqui, fazer uma comparação entre aquilo que Gumbrecht denomina "jogo de máscara do autor" e a "função do autor", apresentada por Michel Foucault no já clássico "O que é um autor?". Algumas proposições de Foucault serão tangencialmente debatidas mais adiante. Cf. FOUCAULT, Michel. 'O que é um autor?'. In: O que é um autor? Lisboa: Vega, 1992.

2 Seria interessante associar tais afirmativas com, por exemplo, o prefácio intitulado "Manual do usuário" escrito pelo próprio Gumbrecht para sugerir um certo tipo de recepção, ou de atenção, do leitor ao seu livro Em 1926. Vivendo no limite do tempo. Cf. GUMBRECHT, Hans Ulrich. Manual do usuário. In: Em 1926. Vivendo no limite do tempo. São Paulo: Record, 1999, p. 9-14.

3 É importante notar que em sua argumentação Gumbrecht descarta as abordagens seqüenciais que estabeleceriam monocausalidades entre a invenção da imprensa, as grandes descobertas, o processo de colonização e o surgimento do sistema burocrático, preferindo trabalhar com a noção de simultaneidade dos acontecimentos, o que significa estabelecer relações plausíveis, e não categóricas.

4 Para uma discussão semelhante àquela apresentada por Gumbrecht, vale a pena conferir o ensaio de Silviano Santiago intitulado "Navegar, é preciso viver", no qual o crítico brasileiro discute a função desempenhada pela Carta de Pero Vaz de Caminha como asseguradora e legitimadora dos direitos da coroa portuguesa - representada pela figura do Rei - sobre as terras achadas além-mar. Cf. SANTIAGO, Silviano. "Navegar é preciso viver. In: NOVAES, Adauto. Tempo e história. São Paulo: Companhia das Letras, 1994.

5 Para uma importante discussão das conseqüências políticas das afirmativas da morte do sujeito e do autor, cf. HUYSSEN, Andreas. "Mapeando o pós-moderno". In: HOLLANDA, Heloísa Buarque de. Pós-moderno e politica. Rio de Janeiro: Rocco, 1991, e, do mesmo autor, "The fate of difference: pluralism, politics, and the postmodern". Amerikastudien/ American Studies, 38, 1993.

6 É preciso esclarecer que, longe de ser uma crítica ao pensamento de Barthes, Foucault e Derrida, o livro de Seán Burke tem sob sua mira a crítica anglo-americana, ou seja, a desconstrução em sua particular apropriação do anti-autorialismo e anti-subjetivismo pós-estruturalista: Leitores atentos do subtexto deste trabalbo notarão que [minha] impaciência não se dirige aos três 'sujeitos' deste livro - poderosos pensadores de seu tempo - mas à instituição crítica anglo-americana, que precison de argumentos de autoridade para a desconstrução da autoridade (BURKE, 1993, p. ix). Esta e as subseqüentes traduções de citações ao texto de Seán Burke são de minha responsabilidade.

7 É possível afirmar que a transferência do corpo teórico pós-estruturalista para o contexto brasileiro efetuou-se, ao contrário do que ocorreu nos EUA, a partir de uma interpretação bastante politizada e contextualizada de seus conceitos, que vieram somar-se a uma reflexão crítica própria, que remonta à antropofagia oswaldiana. Sobre esta questão, cf. o ensaio de Eneida Maria de Souza, "Sujeito e identidade cultural”. In: Traço crítico. Belo Horizonte/Rio de Janeiro: UFMG/UFRJ, 1993, e, de Silviano Santiago, "O entre-lugar do discurso latino americano", In: Uma literatura nos trópicos. São Paulo: Perspectiva, 1978, e o ensaio "Democratização no Brasil - 1979-1981. (Cultura versus Arte)". In: ANTELO, Raul (org.). Declinio da arte. Ascensão da cultura. Florianópolis: Letras Contemporâneas e Abralic, 1998, sobretudo a nota $\mathrm{n}^{\circ} 8$.

8 Em relação à questão da linguagem como categoria transcendente, é preciso ter em mente as variações de status atribuído à linguagem pelos diferentes pensadores pós-estruturalistas.

9 Em contexto brasileiro, Silviano Santiago já apontava, em "Prosa literária atual no Brasil” (1984), para o então crescente interesse dos estudos literários por discursos autobiográficos e biográficos - também denominados discursos de construção de selves-, bem como para os aspectos referenciais autobiográficos e biográficos que permeiam discursos ficcionais. Naquele artigo, Santiago apontava para a necessidade de pousarmos os olhos sobre aquilo que ele denominava como "o corpo-vivo que está por detrás da escrita" (p. 31). Ainda que por razões diversas daquelas apontadas por Gumbrecht como as constelações que 
favoreceram o surgimento das noções de autor e sujeito na Modernidade e daquelas apontadas por Seán Burke ao referir-se à discussão suscitada pelo 'caso de Man', Silviano Santiago alertava então para a necessidade de vincular textos a seus autores e aos sujeitos a partir dos quais os discursos e comunicados associados a esses textos são emitidos.

\section{REFERÊNCIAS}

BURKE, Seán. The death and return of the autor. Criticism and subjectivity in Barthes, Foucault and Derrida. Edinburgh UP, 1993.

GUMBRECHT, Hans Ulrich. "Autor como máscara: contribuição a uma arqueologia do impresso" e "Garcilaso de la Vega, el Inca. Nascimento do sujeito a partir do sistema da burocracia". In: Modernização dos sentidos. São Paulo: Ed. 34, 1998.

HUYSSEN, Andreas. "Mapeando o pós-moderno”. In: HOLLANDA, Heloísa Buarque de. Pós-moderno e política. Rio de Janeiro: Rocco, 1991.

HUYSSEN, Andreas. "The fate of difference: pluralism, politics, and the postmodern". Amerikastudien/ American Studies, 38, 1993.

OLINTO, Heidrun Krieger. "Letras na página / Palavras no Mundo: novos acentos sobre estudos de literatura". Palavra, n. 1, 1993, pp. 7-40

SANTIAGO, Silviano. "Prosa literária atual no Brasil". In: das Letras, 1989.

SCHMIDT, Siegfried. "Do texto ao sistema literário. Esboço de uma ciência da literatura empírica construtivista”. In: OLINTO, Heidrun Krieger (org.). Ciência da literatura empírica. Rio de Janeiro: Tempo Brasileiro, 1994.

SCHMIDT, Siegfried. "On the construction of fiction and the invention of facts". Poetics 18, 1989.

VERSIANI, Daniela Beccaccia. Autoetnografias. Conceitos alternativos em construção. Rio de Janeiro: 7Letras, 2005.

Reflexões sobre o surgimento, a morte e o retorno das noções de autor e sujeito Reflection on the advent, death and return of the notions of author and subject

\section{RESUMO}

Este ensaio discute as reflexões de dois pensadores contemporâneos sobre os conceitos de autor e sujeito. Inicialmente apresenta a constelação de três fatores que, segundo Hans Ulrich Gumbrecht, teriam possibilitado, na era moderna, o surgimento das noções de autor e sujeito: a institucionalização da técnica de impressão de textos e sua conseqüente circulação independente da presença física de seu autor; o processo de colonização da América e o surgimento do sistema burocrático. Em seguida, resume a discussão levantada por Seán Burke sobre as conseqüências éticas e políticas das afirmativas pós-estruturalistas do fim das categorias de autor e de sujeito, que marcaram boa parte das discussões filosóficas e teórico-literárias da segunda metade do século XX. Por fim, sugere a retomada das noções de sujeito e autor vinculadas agora à necessidade de construir a visibilidade social, cultural e política de novas e alternativas subjetividades bem como uma episteme aberta e plural. 


\section{ABSTRAC}

This essay discusses the reflections of two contemporary thinkers about the concepts of the author and the subject. At first, it presents three factors which would give possibility, in modern age, to the emergence of the notions of the author and the subject: the institutionalization of press and subsequent circulation of texts without the physical presence of the author; the process of colonization of America, and the emergence of the bureaucratic system. Secondly, this essay presents the discussion raised by Seán Burke about ethical and political consequences of the poststructuralist statements about the end of the cathegories of the author and the subject, which characterized a large part of the philosophical, theoretical and literary debates since the second half of the Twenty century. Finally, it suggest the return of the notions of the author and the subject, now associated to the need of constructing social, cultural and political visibility for alternatives and new subjectivities as well as for a more plural and open episteme.

Recebido: $16 / 10 / 2007$

Aprovado: 05/03/2008

Daniela Beccaccia Versiana é docente da graduação e da pós-graduação da PUC-RJ. Doutora em Letras pela mesma universidade, em 2002, com a tese Autobiografias. Conceitos alternativos em construção (Rio de Janeiro: 7Letras: 2005). Pesquisa os temas como: teorias contemporâneas da literatura e da antropologia, historiografia literária, literatura comparada e estudos culturais. Publicou três livros de ficção e traduziu algumas das principais obras do pensador italiano Norberto Bobbio. 